\title{
Radiator Heat Dissipation Performance
}

\author{
Toure Ismael, Sheng Bu Yun, Fayzimatov Ulugbek \\ Department of Mechanical and Electronic Engineering, Wuhan University of Technology, Wuhan, China \\ Email: ismomahamat84@yahoo.fr, shengby@whut.edu.cn
}

Received 2 June 2016; accepted 20 June 2016; published 23 June 2016

Copyright (C) 2016 by authors and Scientific Research Publishing Inc.

This work is licensed under the Creative Commons Attribution International License (CC BY).

http://creativecommons.org/licenses/by/4.0/

(c) (i) Open Access

\section{Abstract}

This paper presents a set of parametric studies of heat dissipation performed on automotive radiators. The work's first step consists of designing five radiators with different fin pitch wave distance $(P=2.5,2.4,2.3,2.2,2.1 \mathrm{~mm})$. Then, we proceed to the fabrication of our five samples. The purpose of this work is to determine through our experiment's results which one have the best cooling performance. This numerical tool has been previously verified and validated using a wide experimental data bank. The analysis focuses on the cooling performance for automobile radiator by changing several dimensions of the radiator fin phase as well as the importance of coolant flow lay-out on the radiator global performance. This experience has been performed at Hubei Radiatech Auto Cooling System Co., Ltd. For the cooling performance experience, we use JB2293-1978 Wind Tunnel Test Method for Automobile and Tractor Radiators. The test bench system is a continuous air suction type wind tunnel; collection and control of operating condition parameters can be done automatically by the computer via the preset program, and also can be done by the user manually. The results show that the more we increase the fin phase, the better the cooling performance will be and we also save material so the product cost will be cheaper.

\section{Keywords}

Fin Pitch, Parametric Studies, Automotive Radiators, Cooling Performance, Wave Distance

\section{Introduction}

The air-cooled heat exchangers found in a vehicle (radiator, AC condenser and evaporator, charge air cooler, etc.) have an important role in its weight and also in the design of its front-end module, which also has a strong impact on the car aerodynamic behavior.

The thermal/structural study of radiators arises mainly because of crack-induced leakage and other failures in the heavy-duty cooling system and the difficulty in pointing out the root of the cause. The radiator is the main component in a cooling package to remove heat from the engines of heavy-duty trucks. Looking at these challenges, an optimization process is compulsory to obtain the best design compromise between performance, size/ 
shape and weight. This experience's objective demands advanced design tools that can indicate not only the best solution but also the fundamental reason of a performance improvement that will satisfy our customers and market demand.

To improve the heat transfer from the surface, we use the B shape tubes which are vital components in the radiator design, the liquid flows in B shape tubes while the air flows in channels set up by multileveled fin surfaces. In many situations, the thermal resistance on the air side is larger than that on the liquid side.

Some previous references were found with experimental analysis of the thermal and fluid-dynamic behavior of automotive radiators. Gollin and Bjork [1] experimentally compared the performance of five commercial radiators working with water and five aqueous glycol mixtures. Lin et al. [2] presented an interesting study of specific dissipation (SD) sensibility to radiator boundary conditions (air and coolant inlet temperatures and mass flow). Ganga Charyulu et al. [3] presented a numerical analysis (based on e_NTU method) of a radiator in a diesel engine, centering the attention on the influence of fin and tube materials and the boundary conditions on both fluids. Thin-wall heat conduction is used for the thermal resistance calculation in the tube. The near-wall formulation, the wall function-based model, is used to calculate the wall shear stresses and heat transfer. Sagot et al. [4] investigated experimentally the heat transfer of a round air jet impinging on a circular flat plate. Kezios [5] investigated heat transfer from an impinging jet to a plane surface limited to the neighborhood of the stagnation point. Lu et al. [6] [7] also adopted the porous medium model to simulate the pressure loss through the horizontal radiator in a small dry cooling tower.

Our work not only improves the radiator heat dissipation performance by changing the fin pitch wave distance but also reduces the material for his conception.

\section{Experience Procedure}

This experience has been performed at Hubei Radiatech Auto Cooling System Co., Ltd. The experience is about the cooling performance for automobile radiator by changing several dimensions of the radiator fin phase.

We first use CATIA software to draw out the 3D design of the radiators as shown in Figure 1 and Figure 2 with different fin wave distance P2.1, P2.2, P2.3, P2.4, P2.5 we need for our experiments. Then, we gave the technical characteristics and 2D schema to the engineer for samples fabrication.

For the cooling performance experience, we use JB2293-1978 Wind Tunnel Test Method for Automobile and Tractor Radiators. The test system is a continuous air suction type wind tunnel, collection and control of operating condition parameters can be done automatically by the computer via the preset program, and also can be done by the user manually.

Two set intake pipes are provided for the equipment to ensure the precision of flow measurement and control. In the meanwhile, there are two air ducts different in size for test pieces that different in core dimension.

The parametric studies presented in this paper have been performed on a louvered radiator that has been experimentally tested in detail for a wide range of working conditions. All numerical tests have been conducted using an axial grid of $20 \mathrm{CV}$ and convergence criteria of $1.0 \mathrm{e}-5$ to close a pseudo-transient resolution process. Both

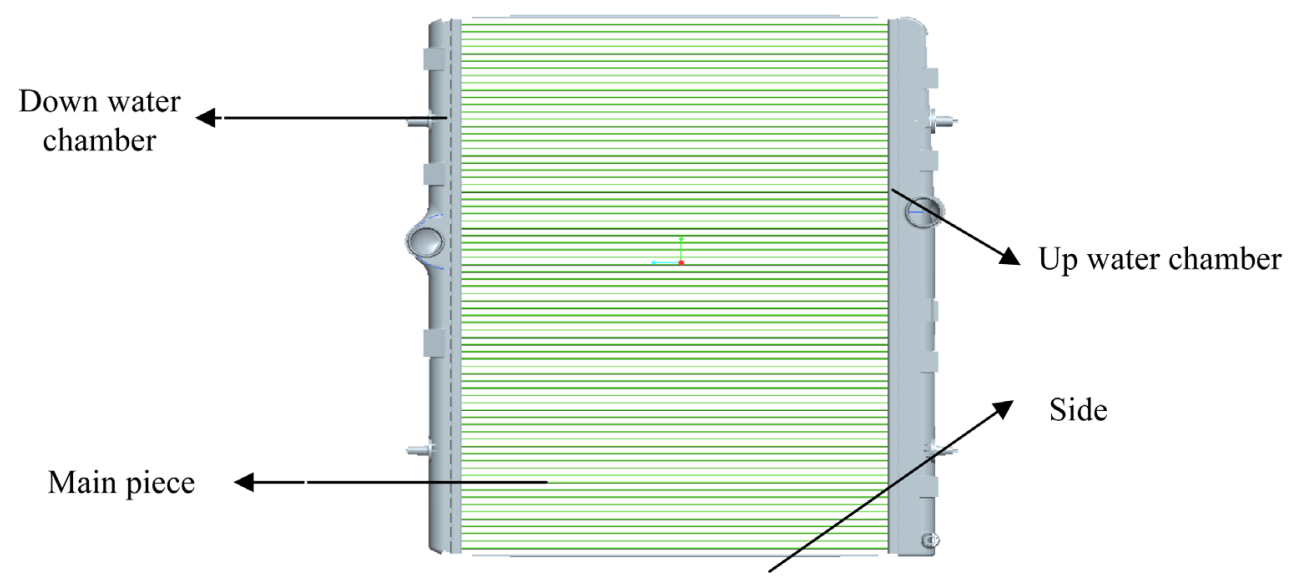

Figure 1. Automobile radiator structure. 

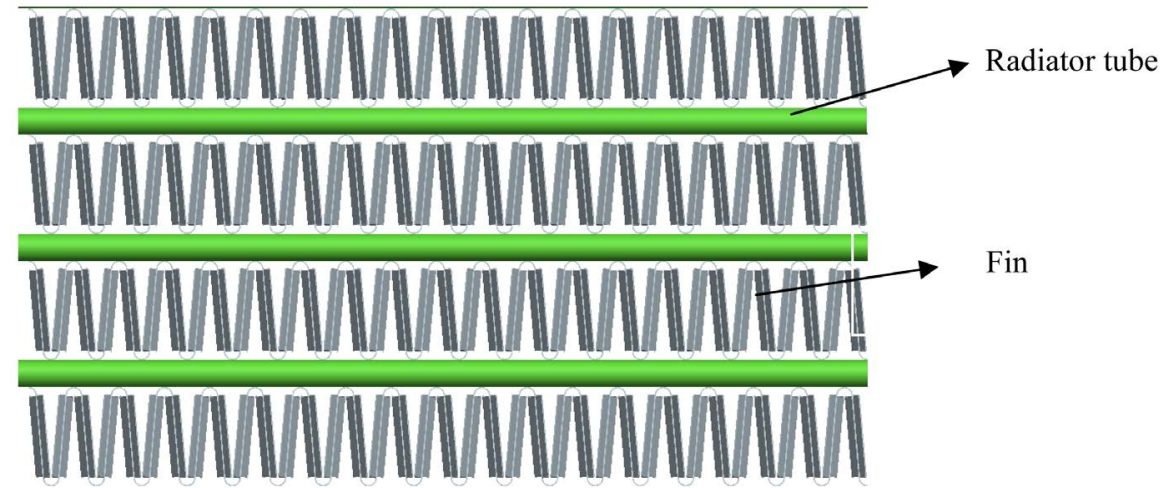

Figure 2. The water tubes and the fins pitch with an enlarged view.

values have been obtained from previous work on the verification of the numerical solutions provided by the heat exchanger model [8]. The wall function-based heat transfer coefficients are given by the following expression [9]:

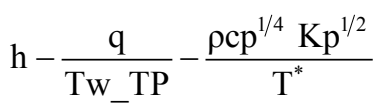

The fin conduction equation and the convective heat transfer with the surrounding air flow have been introduced by using fundamental heat transfer procedures, considering a negligible temperature variation through the fin thickness and that both the air temperature and the heat transfer coefficient are uniform over the fin surface of each control volume.

The calculation of these efficiencies is briefly shown in Equation (2), where $\mathrm{j}$ indicates the control volume height indexing.

$$
\eta_{\mathrm{a}} \mathrm{F}=\frac{\mathcal{Q}_{\mathrm{a}} \mathrm{F}_{\mathrm{j}-1}+\mathcal{Q}_{\mathrm{a}} \mathrm{F}_{\mathrm{j}+1}}{\alpha_{\mathrm{a}}\left(\mathrm{T}_{\mathrm{a}}-\mathrm{T}_{T}\right) \mathrm{AF}}
$$

The energy conservation equation is applied to the tube element for each macro control volume, considering thermal interactions with the surrounding sets of fins, the air and coolant flows, and the neighbor tube control volumes as shown in Figure 3. Heat convection from the air and coolant flows is determined by the use of the corresponding local heat transfer coefficients and temperatures at each time step and iteration. The method has clear advantages over semi-analytical and semi-empirical methods that have evolved in the past for the concept design and performance rating applications that appear in many heat exchanger books [10]-[12].

\section{Tables and Figures of Experiences}

\subsection{Experience Result}

The first experience consists of observing the five samples cooling performance in the JB2293-1978 Wind Tunnel Test by using the same liquid flow for each one, and then we repeated the same experience by changing the liquid flow $(50 \mathrm{~L} / \mathrm{min}, 83.3 \mathrm{~L} / \mathrm{min}, 100 \mathrm{~L} / \mathrm{min}$ and $133.3 \mathrm{~L} / \mathrm{min})$. Fin pitch is one of the most important design parameters in this kind of heat exchangers, because its great influence on the global heat transfer rate of the equipment and its easy industrial implementation. Fin pitches from 2.5 to $2.1 \mathrm{~mm}$ have been considered, heat transfer and pressure drop results are presented from Tables 1-5 for a better understanding of the global thermal and hydraulic heat exchanger performance.

\subsection{Experience Result in Discussion}

We can observe through our experience's results that P2.5, 2.4, 2.3, 2.2, 2.1 have some common air velocities $(3,5,6,8,10 \mathrm{~m} / \mathrm{s})$. We also observe some little differences of the liquid flow rates between our five samples because of the fabrication condition, but we will not consider it because the difference is very small. In this case UA has been taken as the enhancement parameter because the heat transfer surface strongly depends on fin pitch. 


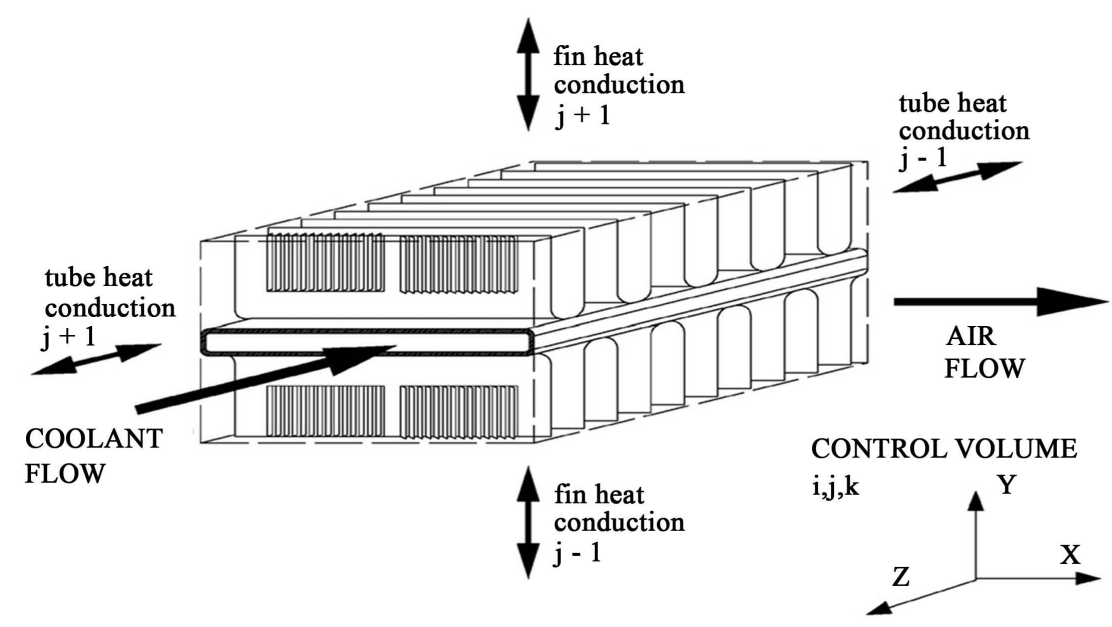

Figure 3. Radiator tube and fin air/coolant volume flow description.

The influence of both the flow rate and the fin pitch on the heat transfers and pressure drop is clearly shown.

From the results, we can also observe that the cooling performance for the same liquid flow rate get better when we increase the air speed flow.

For example: $\mathrm{Gw}=50.7 \mathrm{~L} / \mathrm{min}, \mathrm{Va}=3.00 \mathrm{~m} / \mathrm{s}$ we have $\mathrm{Qn}=31.12 \mathrm{Kw}$ is less than for $\mathrm{Qw}=50.7 \mathrm{~L} / \mathrm{min}, \mathrm{Va}$ $=5.00 \mathrm{~m} / \mathrm{s}$ whom cooling performance equal $41.45 \mathrm{Kw}$.

By using $\frac{\mathrm{Qn} 2-\mathrm{Qn} 1}{\mathrm{Qn} 1}$ to evaluate the heat performance rate from Table 1 to Table 2 we can observe that the heat transfer rate on increases about $0.7 \%$ to $1.8 \%$ and, $\Delta \mathrm{Pw}$ also increases from $\mathrm{Gw}(50.7-165.8 \mathrm{~L} / \mathrm{min})$ to about $2 \%$ to $5 \%$. This is important to know but it is not our research main objective. Our work consists to increase the heat performance of our radiator by changing its fin pitch wave distance and structure.

From Tables 1-5 we can observe that the more we increase the fin wave distance better will be the heat performance. To show the cooling performance results we will compare our experience's results of Tables 1-5, by using $\frac{\mathrm{Qn} 2-\mathrm{Qn} 1}{\mathrm{Qn} 1}$.

For $\mathrm{P}=2.5(\mathrm{Va}=3.00 \mathrm{~m} / \mathrm{s}, \mathrm{Gw}=50.5 \mathrm{~L} / \mathrm{min}, \mathrm{Qn}=30.90 \mathrm{Kw})$ and $\mathrm{P}=2.1(\mathrm{Va}=3.00 \mathrm{~m} / \mathrm{s}, \mathrm{Gw}=50.5 \mathrm{~L} / \mathrm{min}$, $\mathrm{Qn}=31.65 \mathrm{Kw})$ we have $2.4 \%$ of heat performance between the two different fin pitch wave distances (P2.4-P2.1).

As show from Figures 4-8 the cooling performance gets better by increasing the liquid flow rate $\mathrm{Gw}(\mathrm{L} / \mathrm{min})$, for example when $\mathrm{Gw}=166 \mathrm{~L} / \mathrm{m}$ we have $7.2 \%$ of cooling performance between (P2.5 - P2.1). It's also the same with the air speed flow $\mathrm{Va}(\mathrm{m} / \mathrm{s})$, for example for $\mathrm{Va}=10.00 \mathrm{~m} / \mathrm{s}$ we have $8.9 \%$ of cooling performance between (P2.5 - P2.1).

But we will focalize on the cooling performance caused by the different wave distances, because that is the main purpose of our research.

Because of our experience large result data, we will focalize just on the last result of Tables 1-5 by using $\frac{\mathrm{Qn} 5-\mathrm{Qn} 1}{\mathrm{Qn1}}$ to show our experience heat dissipation performance; Qn5 $=77.47 \mathrm{Kw}(\mathrm{Gw}=166.1 \mathrm{~L} / \mathrm{min}, \mathrm{Va}=$ $10.00 \mathrm{~m} / \mathrm{s})$

$$
\mathrm{Qn} 1=69.65 \mathrm{Kw}(\mathrm{Gw}=165.7 \mathrm{~L} / \mathrm{min}, \mathrm{Va}=10 \mathrm{~m} / \mathrm{s})
$$

$$
\frac{\mathrm{Qn} 5-\mathrm{Qn} 1}{\mathrm{Qn} 1} \rightarrow \frac{77.47-69.65}{60.65}=0.1122=11 \%
$$

we can observe that the more we increase the fin pitch distance better will get our radiator heating dissipation performance. The experience's results calculation by using $\frac{\mathrm{Qn} 5-\mathrm{Qn} 1}{\mathrm{Qn1}}$ show us that by changing the radiator fin pitch wave distance from $\mathrm{P}=2.5 \mathrm{~mm}$ to $\mathrm{P}=2.1 \mathrm{~mm}$, the cooling performance increases about $11 \%$. 


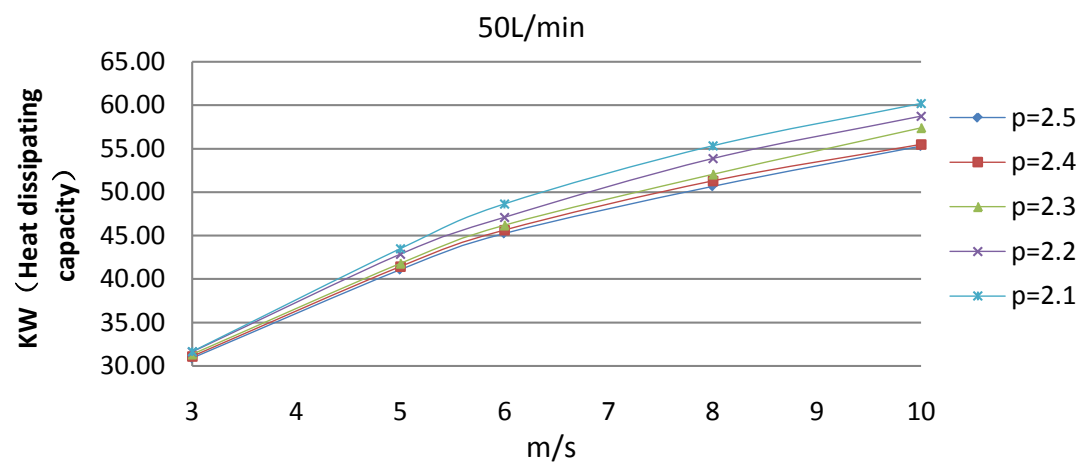

Figure 4. Heat dissipating capacity comparison (with same flow rate but different fin pitch waves length).

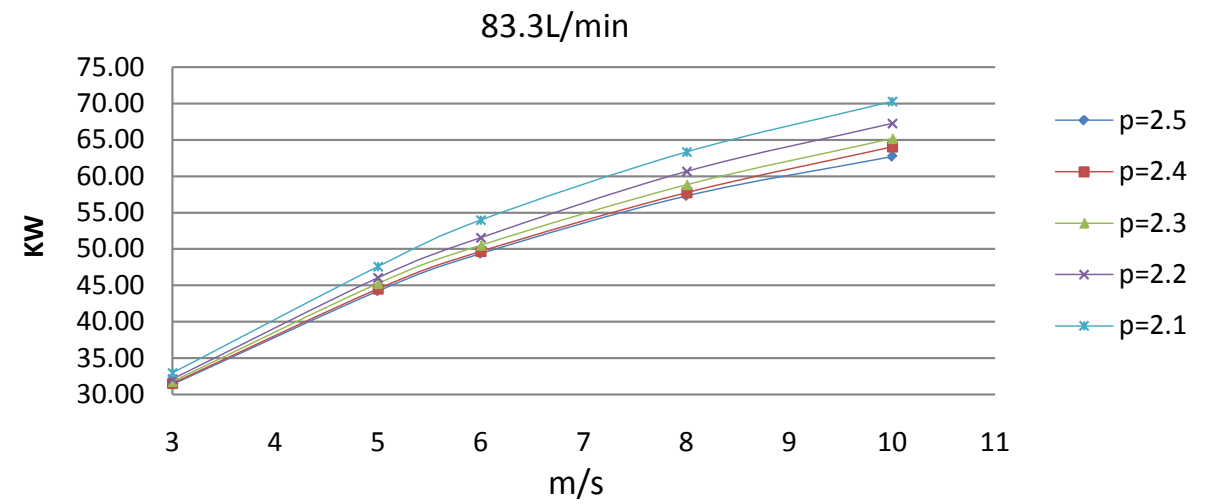

Figure 5. Heat dissipating capacity comparison (with same flow rate but different fin pitch waves length).

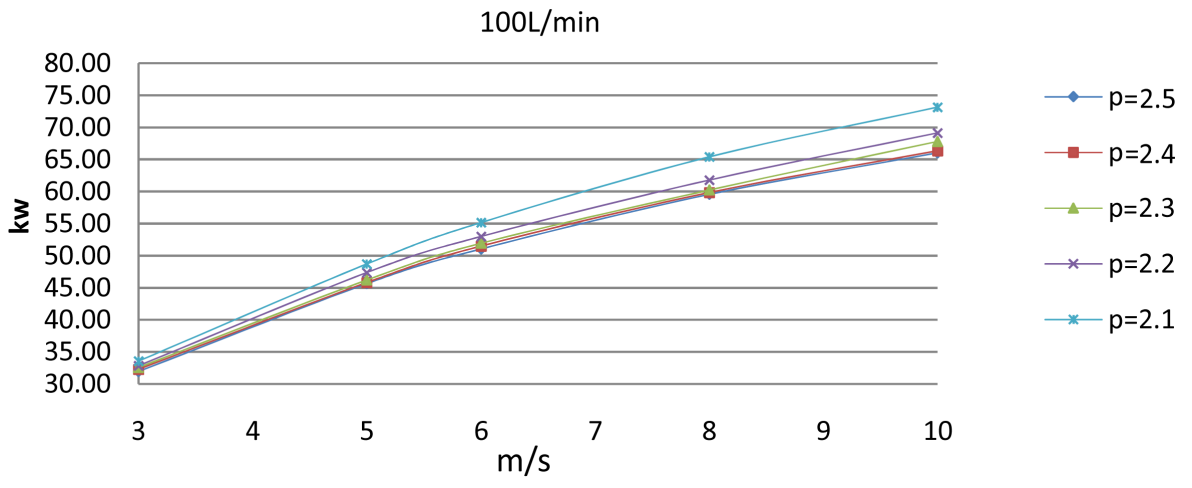

Figure 6. Heat dissipating capacity comparison (with same flow rate but different fin pitch waves length).

Table 1. $\mathrm{P}=2.5 \mathrm{~mm}$.

\begin{tabular}{|c|c|c|c|c|c|c|}
\hline $\mathrm{Va}(\mathrm{m} / \mathrm{s})$ & & & & & & \\
\hline Qn (kw) & 3.00 & 5.00 & 6.00 & 8.00 & 10.00 & $\Delta \mathrm{Pw}(\mathrm{kPa})$ \\
\hline \multicolumn{7}{|l|}{$\mathrm{Gw}(\mathrm{L} / \mathrm{min})$} \\
\hline 50.5 & 30.90 & 41.08 & 45.25 & 50.67 & 55.30 & 12.26 \\
\hline 82.3 & 31.38 & 44.24 & 49.37 & 57.30 & 62.73 & 24.22 \\
\hline 99.1 & 31.93 & 45.63 & 51.06 & 59.57 & 66.04 & 32.72 \\
\hline 132.3 & 32.33 & 46.81 & 52.51 & 61.24 & 67.81 & 54.10 \\
\hline 165.7 & 33.09 & 48.06 & 53.87 & 62.49 & 69.65 & 83.22 \\
\hline$\Delta \mathrm{Pa}(\mathrm{Pa})$ & 67 & 149 & 195 & 300 & 428 & - \\
\hline
\end{tabular}




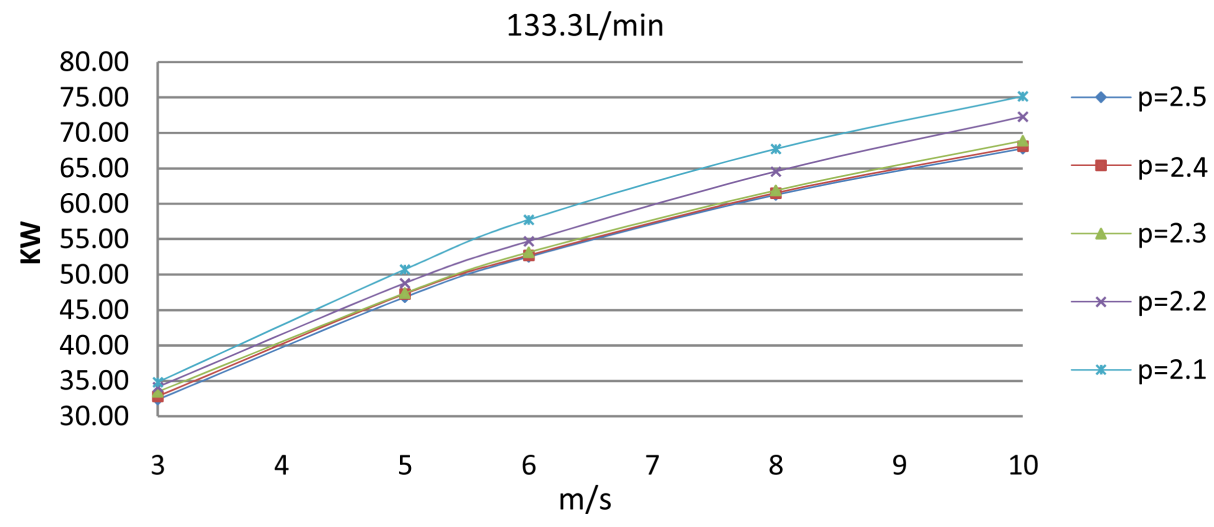

Figure 7. Heat dissipating capacity comparison (with same flow rate but different fin pitch waves length).

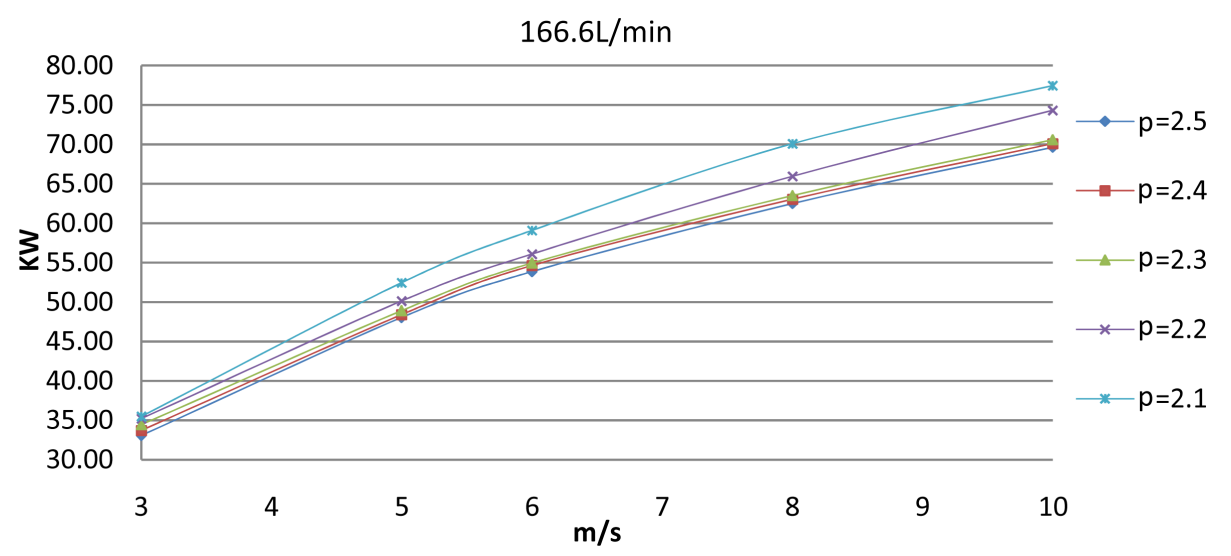

Figure 8. Heat dissipating capacity comparison (with same flow rate but different fin pitch waves length).

Table 2. $\mathrm{P}=2.4 \mathrm{~mm}$.

\begin{tabular}{|c|c|c|c|c|c|c|}
\hline $\mathrm{Va}(\mathrm{m} / \mathrm{s})$ & & & & & & \\
\hline Qn (kw) & 3.00 & 5.00 & 6.00 & 8.00 & 10.00 & $\Delta \mathrm{Pw}(\mathrm{kPa})$ \\
\hline \multicolumn{7}{|l|}{$\mathrm{Gw}(\mathrm{L} / \mathrm{min})$} \\
\hline 50.7 & 31.12 & 41.45 & 45.63 & 51.28 & 55.50 & 11.64 \\
\hline 82.7 & 31.53 & 44.52 & 49.65 & 57.77 & 64.05 & 23.38 \\
\hline 99.0 & 32.27 & 45.82 & 51.51 & 59.84 & 66.35 & 31.50 \\
\hline 132.4 & 32.80 & 47.25 & 52.73 & 61.52 & 68.16 & 52.66 \\
\hline 165.8 & 33.70 & 48.38 & 54.63 & 63.04 & 70.07 & 81.30 \\
\hline$\Delta \mathrm{Pa}(\mathrm{Pa})$ & 70 & 153 & 202 & 311 & 443 & - \\
\hline
\end{tabular}

Table 3. $\mathrm{P}=2.3 \mathrm{~mm}$.

\begin{tabular}{|c|c|c|c|c|c|c|}
\hline $\mathrm{Va}(\mathrm{m} / \mathrm{s})$ & & & & & & \\
\hline Qn (kw) & 3.00 & 5.00 & 6.00 & 8.00 & 10.00 & $\Delta \mathrm{Pw}(\mathrm{kPa})$ \\
\hline \multicolumn{7}{|l|}{$\mathrm{Gw}(\mathrm{L} / \mathrm{min})$} \\
\hline 50.6 & 31.34 & 41.79 & 46.20 & 52.05 & 57.42 & 11.60 \\
\hline 83.1 & 31.75 & 45.24 & 50.51 & 58.82 & 65.20 & 24.22 \\
\hline 99.6 & 32.58 & 46.21 & 51.95 & 60.25 & 67.82 & 32.88 \\
\hline 133.2 & 33.47 & 47.39 & 53.14 & 61.86 & 68.87 & 55.28 \\
\hline 165.9 & 34.42 & 48.89 & 54.94 & 63.51 & 70.60 & 85.74 \\
\hline$\Delta \mathrm{Pa}(\mathrm{Pa})$ & 76 & 166 & 219 & 337 & 483 & 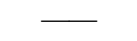 \\
\hline
\end{tabular}


Table $4 . \mathrm{P}=2.2 \mathrm{~mm}$.

\begin{tabular}{|c|c|c|c|c|c|c|}
\hline $\mathrm{Va}(\mathrm{m} / \mathrm{s})$ & & & & & & \\
\hline Qn (kw) & 3.00 & 5.00 & 6.00 & 8.00 & 10.00 & $\Delta \mathrm{Pw}(\mathrm{kPa})$ \\
\hline \multicolumn{7}{|l|}{$\mathrm{Gw}(\mathrm{L} / \mathrm{min})$} \\
\hline 50.7 & 31.61 & 42.85 & 47.11 & 53.87 & 58.75 & 11.70 \\
\hline 82.9 & 32.14 & 46.04 & 51.56 & 60.67 & 67.25 & 23.96 \\
\hline 99.1 & 32.86 & 47.36 & 53.00 & 61.82 & 69.16 & 32.42 \\
\hline 132.5 & 34.14 & 48.77 & 54.70 & 64.55 & 72.28 & 54.32 \\
\hline 165.8 & 35.23 & 50.12 & 56.09 & 65.95 & 74.34 & 84.40 \\
\hline$\Delta \mathrm{Pa}(\mathrm{Pa})$ & 82 & 177 & 233 & 356 & 512 & - \\
\hline
\end{tabular}

Table 5. $\mathrm{P}=2.1 \mathrm{~mm}$.

\begin{tabular}{|c|c|c|c|c|c|c|}
\hline $\mathrm{Va}(\mathrm{m} / \mathrm{s})$ & & & & & & \\
\hline Qn (kw) & 3.00 & 5.00 & 6.00 & 8.00 & 10.00 & $\Delta \mathrm{Pw}(\mathrm{kPa})$ \\
\hline \multicolumn{7}{|l|}{$\mathrm{Gw}(\mathrm{L} / \mathrm{min})$} \\
\hline 50.5 & 31.65 & 43.51 & 48.63 & 55.33 & 60.23 & 12.12 \\
\hline 82.9 & 32.98 & 47.60 & 53.97 & 63.36 & 70.32 & 24.40 \\
\hline 99.7 & 33.57 & 48.69 & 55.19 & 65.41 & 73.20 & 33.18 \\
\hline 133.0 & 34.82 & 50.72 & 57.74 & 67.76 & 75.19 & 54.78 \\
\hline 166.1 & 35.47 & 52.45 & 59.0аaа & 70.07 & 77.47 & 83.70 \\
\hline$\Delta \mathrm{Pa}(\mathrm{Pa})$ & 88 & 190 & 249 & 382 & 551 & - \\
\hline
\end{tabular}

Moreover, the results also show that we can use less material for the radiator and still have better cooling performance, so meaning that the price will be cheaper and will give our product good competiveness in the market.

\section{Conclusions}

A set of numerical parametric studies on automotive radiators has been presented in details in this paper, analyzing the influence of those parameters on the full thermal and hydraulic behavior of the heat exchanger.

The first part of the parametric studies has focused on the influence of working conditions on some different designs of geometrical parameters (fin spacing, louver angle) as well as the importance of coolant flow lay-out on the radiator global performance.

This work provides a detailed example of the overall behavior report of an automobile radiator working at a usual range of operating conditions. Significant knowledge-based design conclusions have also been reported.

From our experiment's results, we observed that by changing the fin pitch wave distance, we use less material for the radiator but also increase his cooling performance. That means the price will be cheaper and will give our product good competiveness in the market. From the five samples of radiators we made, we choose $\mathrm{P}=2.1$ because it has the best cooling performance and is the one which uses less material.

The next step of our work is to study the life performance (FEMA) of our radiator.

\section{Acknowledgements}

The first author would like to express his gratitude to Hubei Radiatech Auto Cooling System Co., LTD for giving us the chance to use the company lab to perform our experience, to our supervisor Mr. Sheng Bu Yun and to Mr. He Zhuang for their prolonged research collaboration and for providing valuable information. 


\section{References}

[1] Gollin, M. and Bjork, D. (1996) Comparative Performance of Ethylene Glycol/ Water and Propylene Glycol/Water Coolants in Automobile Radiators. SAE Technical Paper Series SP-1175, 960372, 115-123.

[2] Lin, C., Saunders, J. and Watkins, S. (2000) The Effect of Changes in Ambient and Coolant Radiator Inlet Temperatures and Coolant Flow Rate on Specific Dissipation. SAE Technical Paper Series (2000-01-0579), 1-12.

[3] Ganga Charyulu, D., Singh, G. and Sharma, J.K. (1999) Performance Evaluation of a Radiator in a Diesel Engine: A Case Study. Applied Thermal Engineering, 19, 625-639. http://dx.doi.org/10.1016/S1359-4311(98)00064-7

[4] Kezios, S.P. (1956) Heat Transfer in the Flow of a Cylindrical Air Jet Normal to an Infinite Plane. PhD Thesis, Illinois Institution, Tech.

[5] Sagot, B., Antonini, G., Christgen, A. and Buron, F. (2008) Jet Impingement Heat Transfer on a Flat Plate at a Constant Wall Temperature. International Journal of Thermal Science, 47, 1610-1619. http://dx.doi.org/10.1016/j.ijthermalsci.2007.10.020

[6] Lu, Y., Guan, Z., Gurgenci, H. and Zou, Z. (2013) Windbreak Walls Reverse the Negative Effect of Crosswind in Short Natural Draft Dry Cooling Towers into a Performance Enhancement. International Journal of Heat and Mass Transfer; 63, 162-170. http://dx.doi.org/10.1016/j.ijheatmasstransfer.2013.03.075

[7] Lu, Y., Gurgenci, H., Guan, Z. and He, S. (2014) The Influence of Windbreak Wall Orientation on the Cooling Performance of Small Natural Draft Dry Cooling Towers. International Journal of Heat and Mass Transfer, 79, 10591069. http://dx.doi.org/10.1016/j.ijheatmasstransfer.2014.09.012

[8] Pe'rez-Segarra, C.D., Oliet, C. and Oliva, A. Thermal and Fluid Dynamic Simulation of Automotive Fin-and-Tube Heat Exchangers. Part 1: Mathematical Model, Heat Transfer Engineering. (To Be Published)

[9] Viegas, J.R., Rubesin, M.W. and Horstman, C.C. (1985) On the Use of Wall Functions as Boundary Conditions for Two-Dimensional Separated Compressible Flow. Technical Report AIAA-85-0180, AIAA 23rd Aerospace Sciences Meeting, Reno, Nevada.

[10] Kakac, S. and Liu, H. (2002) Heat Exchangers. 2nd Edition, CRC, 1446.

[11] Kartushinsky, A. and Michaelides, E.E. (2004) An Analytical Approach for the Closure Equations of Gas-Solid Flows with Inter-Particle Collisions. International Journal of Multiphase Flow, 30, 159-180.

[12] Kays, W.M. and London, A.L. (1984) Compact Heat Exchangers. 3rd Edition, McGraw-Hill, New York. 


\section{Baseline Geometry Description of the Automobile Radiator under Study}

Core thickness (mm)

18

Core height $(\mathrm{mm})$

Core width $(\mathrm{mm})$

562

Rows

Total tubes 79

Tube dimensions ( $\mathrm{mm})$

$400 \times 16$

Tube thickness (mm)

0.29

Tube pitch (mm)

Fin pitch (mm)

Fin thickness (mm)

\section{Nomenclature}

$\mathrm{P} \quad$ wave distance, $(\mathrm{mm})$

$\mathrm{F} \quad$ fin pitch, (mm)

Qn Heath transfers rate, $(\mathrm{Kw})$

Qw Liquid flow rate $(\mathrm{L} / \mathrm{min})$

$\mathrm{Va} \quad$ Air speed flow, $(\mathrm{m} / \mathrm{s})$

$\triangle \mathrm{Pa} \quad$ Air pressure flow, $(\mathrm{Pa})$

$\Delta \mathrm{Pw} \quad$ Inside water pressure flow, (Kpa)

$\mathrm{Cp} \quad$ Specific heat at constant pressure, $\left(\mathrm{J} \cdot \mathrm{kg}^{-1} \cdot \mathrm{K}^{-1}\right)$
1.6

5.5

0.07

Submit or recommend next manuscript to SCIRP and we will provide best service for you:

Accepting pre-submission inquiries through Email, Facebook, Linkedin, Twitter, etc A wide selection of journals (inclusive of 9 subjects, more than 200 journals)

Providing a 24-hour high-quality service

User-friendly online submission system

Fair and swift peer-review system

Efficient typesetting and proofreading procedure

Display of the result of downloads and visits, as well as the number of cited articles

Maximum dissemination of your research work

Submit your manuscript at: http://papersubmission.scirp.org/ 